\title{
High Dose Anticholinergic Therapy in Adult Dystonia
}

\author{
Anthony E. Lang
}

\begin{abstract}
ABSTRAC' : Forty-four adult patients with various forms of dystonia were treated with anticholinergics slowly increased to maximum tolerated doses. Thirty-seven per cent of the 35 idiopathic dystonia patients had a moderate to marked improvement with an average dosage of $21.5 \mathrm{mg}$ of trihexyphenidyl. Younger patients with a shorter duration of dystonia and those who tolerated higher doses tended to benefit most. However there were exceptions to all of these factors. None of the nine patients with symptomatic dystonias improved more than mildly and most had no benefit despite the use of dosages similar to those resulting in improvement in idiopathic dystonia patients. Side effects were common. These often forced drug withdrawal at lower doses than those which might have resulted in improvement. These results suggest that high dose anticholinergics should be the first line of therapy for disabling dystonia.
\end{abstract}

RÉSUMÉ: Thérapie anticholinergique à haute dose dans la dystonie adulte Nous avons traité 44 patients adultes souffrant de diverses formes de dystonie avec des doses croissantes d'anticholinergiques jusqu'à tolérance maximale. $37 \%$ des 35 patients souffrant de dystonie idiopathique éprouvèrent des améliorations modérées à marquées avec une doses moyenne de $21.5 \mathrm{mg}$ de trihexyphénidyle. Les patients plus jeunes dont l'évolution était plus courte et ceux qui toléraient les plus hautes doses semblaient le plus bénéficier de ce traitement. Mais il y avait des exceptions à ces règles. Aucun des 9 sujets avec dystonie symptômatique n'a été amélioré de façon significative, même avec des doses semblables à celles assurant un succès dans la dystonie idiopathique. Les effets secondaires furent fréquents. Dans plusieurs cas ces effets nuisibles ont causé le retrait du médicament à des doses inférieures à celles qui normalement procurent une amélioration clinique. Ces résultats suggèrent que l'emploi de hautes doses d'anticholinergiques devrait constituer le traitement d'attaque dans la dystonie.

Can. J. Neurol. Sci. 1986; 13:42-46

Based on the striking response of neuroleptic-induced acute dystonic reactions to anticholinergic agents, Fahn ${ }^{1}$ first investigated high dose oral anticholinergic therapy in other forms of dystonia. Only two groups to date have published on this treatment in large numbers of dystonic patients. ${ }^{1.4}$ This report discusses the results of attempted high dose anticholinergic therapy in 44 adult patients with various forms of dystonia.

\section{Patients and Methods}

Table 1 tabulates the details of the 44 patients treated. All patients were over 18 years of age at the beginning of therapy with the exception of one patient with idiopathic generalized dystonia who was 16 . Six patients with idiopathic dystonia (three generalized and three segmental) had onset before age 20 (mean age 11) as did two patients with symptomatic dystonia (one post traumatic onset age 6 and one generalized dystonia due to metachromatic leukodystrophy ${ }^{5}$ onset age 8 ). The presence of associated tremor in the patient and a positive family history for dystonia and/or tremor were also recorded to determine if these might be predictive factors for the response to anticholinergics. No patient had diurnal fluctuations in their dystonia $^{6}$ or a "dystonia-parkinsonism" syndrome. ${ }^{7}$

All but two patients were treated with trihexyphenidyl. Ethopropazine only (maximum tolerated dose $450 \mathrm{mg}$ ) was used in one patient with cranial dystonia and benztropine (maximum tolerated dose $12 \mathrm{mg}$ ) was used in one patient with tardive segmental dystonia. Three patients who were unable to tolerate lower doses of trihexyphenidyl were given a separate trial of ethopropazine. Concomitant medication taken at the

From the Movement Disorder Clinic, Toronto Western Hospital

Received July 9, 1985. Accepted October 15, 1985

Reprint requests to: Dr. Anthony E. Lang, Movement Disorder Clinic, Toronto Western Hospital. 399 Bathurst Street, Toronto, Ontario, Canada M5T 2R2 


\begin{tabular}{|c|c|c|c|c|c|c|c|}
\hline \multirow[b]{2}{*}{ Type of Dystonia } & \multirow[b]{2}{*}{ Number } & \multirow{2}{*}{$\begin{array}{l}\text { Sex } \\
\text { M/F }\end{array}$} & \multirow{2}{*}{$\begin{array}{l}\text { Age of Onset } \\
\text { Mean (range) }\end{array}$} & \multirow{2}{*}{$\begin{array}{c}\text { Duration of } \\
\text { Dystonia } \\
\text { Mean (range) }\end{array}$} & \multirow{2}{*}{$\begin{array}{l}\text { No. of } \\
\text { Patients with } \\
\text { Tremor }\end{array}$} & \multicolumn{2}{|c|}{ Family History } \\
\hline & & & & & & Tremor & Dystonia \\
\hline \multicolumn{8}{|l|}{ Idiopathic Dystonia } \\
\hline Generalized & 5 & $1 / 4$ & $\begin{array}{c}19.2 \\
(9-39)\end{array}$ & $\begin{array}{c}9.4 \\
(4-20)\end{array}$ & 1 & 1 & 1 \\
\hline Cranial Dystonia & 6 & $1 / 5$ & $\begin{array}{c}57.8 \\
(42-80)\end{array}$ & $\begin{array}{c}3.4 \\
(1-14)\end{array}$ & 3 & 0 & 0 \\
\hline Spasmodic Torticollis & 12 & $6 / 6$ & $\begin{array}{c}38.6 \\
(25-55)\end{array}$ & $\begin{array}{c}3.0 \\
(0.3-8)\end{array}$ & 3 & 2 & 0 \\
\hline Focal Arm & $3^{*}$ & $1 / 2$ & $\begin{array}{c}33.6 \\
(28-43)\end{array}$ & $\begin{array}{r}1.3 \\
(1-2)\end{array}$ & 2 & 0 & 1 \\
\hline Tardive: Segmental & 3 & $2 / 1$ & $\begin{array}{l}25 \\
(20-29)\end{array}$ & $\begin{array}{c}4 \\
(1-9)\end{array}$ & - & - & 一 \\
\hline Cranial & 2 & $1 / 1$ & $\begin{array}{c}49 \\
(45-53)\end{array}$ & $\begin{array}{r}2.5 \\
(1-4)\end{array}$ & - & - & - \\
\hline Hemidystonia & $3^{+}$ & $2 / 1$ & $\begin{array}{c}43.3 \\
(6-64)\end{array}$ & $\begin{array}{c}7.8 \\
(0.5-14)\end{array}$ & - & - & - \\
\hline Metachromatic Leukodystrophy & 1 & $0 / 1$ & 8 & 34 & - & - & - \\
\hline Sub-total & 9 & $5 / 4$ & $\begin{array}{c}34.5 \\
(6-64)\end{array}$ & $\begin{array}{c}8.2 \\
(0.5-34)\end{array}$ & - & - & - \\
\hline Total: & 44 & $19 / 25$ & $\begin{array}{c}35.6 \\
(6-80)\end{array}$ & $\begin{array}{c}8.9 \\
(0.3-34)\end{array}$ & & & \\
\hline
\end{tabular}

\footnotetext{
*1 Dystonia on many actions $\quad+1$ Post Traumatic

2 Simple writer's cramp 2 Post Stroke
}

time of trihexyphenidyl therapy included haloperidol $2.5 \mathrm{mg} / \mathrm{d}$ in one patient with spasmodic torticollis, and tetrabenazine $62.5 \mathrm{mg} / \mathrm{d}$ in one with tardive segmental dystonia.

Trihexyphenidyl was begun in a dose of $2 \mathrm{mg}$ twice to three times per day and increased by 2 mg every one to two weeks (most often every two weeks). Those patients experiencing intolerable side effects during the initiation of therapy had their dosage reduced to as little as $1 \mathrm{mg}$ daily and increased more slowly as tolerated. Doses were increased until the patient obtained an excellent response or until intolerable side effects occurred. Patients who obtained a useful response and later developed severe adverse effects, had their dosage reduced until adverse effects remitted. The dose was then kept at this new stable level and occasionally further attempts to reach higher doses were made.

All patients who were started on anticholinergics with the intention of slowly increasing to maximum tolerated doses were included in the study. This allowed determination of the frequency of response to high dose anticholinergics as well as the frequency of early drop outs due to intolerable side effects occurring at low doses. Several patients started on anticholinergic therapy during the course of this study were excluded because follow-up was not carried out by the author himself.

Side effects occurring with anticholinergic therapy were separated into "central" (e.g., drowsiness, agitation, difficulty concentrating, "light headedness", decreased coordination, difficulty sleeping) and "peripheral" (e.g., dry mouth, blurred vision, constipation, difficulty voiding, nausea). This was done in order to determine how often treatment with a peripherally acting cholinergic agonist might have permitted the use of higher doses of anticholinergic therapy.

Response to therapy at the maximum tolerated dosage was rated as marked $(+++)$ with little or no dystonia remaining; moderate $(++)$ with dystonia still quite evident; mild $(+)$ with definite reduction in dystonia but little functional improvement; minimal $(+1-)$ or questionable reduction in dystonia and no functional improvement; no benefit $(0)$; and worse ( - ) with an increase in dystonia and disability. Patients were also rated in outcome categories as (A) improved and continuing on maximum dose; (B) improved with side effects, continuing on lower dose; (C) improved but at the expense of intolerable side effects (peripheral or central) causing drug withdrawal; or (D) no significant improvement or intolerable side effects (peripheral or central) without benefit, drug withdrawn.

\section{RESULTS}

\section{Idiopathic Dystonia}

Table 2 outlines the response in the 35 patients with idiopathic dystonia. Thirteen (37\%) had a moderate or marked improvement with an average dose of $21.5 \mathrm{mg} / \mathrm{d}$ of trihexyphenidyl in 12 and $450 \mathrm{mg}$ of ethopropazine in one. Of these, six patients continued on the maximum dosage for more than six months 


\begin{tabular}{|c|c|c|c|c|c|c|}
\hline Age of Onset (yrs) & $\begin{array}{c}37 \\
(28-52)\end{array}$ & $\begin{array}{c}38.3 \\
(17-55)\end{array}$ & $\begin{array}{c}29.8 \\
(8-53)\end{array}$ & $\begin{array}{c}39.5 \\
(8-63)\end{array}$ & $\begin{array}{c}33.3 \\
(7-80)\end{array}$ & 43 \\
\hline Duration of Dystonia (yrs) & $\begin{array}{c}1.1 \\
(0.5-1.5)\end{array}$ & $\begin{array}{c}6.6 \\
(1.5-14)\end{array}$ & $\begin{array}{l}10 \\
(2-20)\end{array}$ & $\begin{array}{c}3.3 \\
(0.5-10)\end{array}$ & $\begin{array}{c}5.4 \\
(0.3-14)\end{array}$ & 1 \\
\hline Median Dosage (mg) & 20 & 20 & 18 & 20 & 12 & 6 \\
\hline \multicolumn{7}{|l|}{ Type of Dystonia } \\
\hline Generalized & 0 & 2 & 2 & 0 & 1 & - \\
\hline Segmental & 0 & 2 & 1 & 2 & 4 & - \\
\hline Cranial Dystonia & $1^{*}$ & 2 & 0 & 1 & 1 & 1 \\
\hline Tremor & 0 & 5 & 0 & 3 & 6 & 0 \\
\hline \multicolumn{7}{|l|}{ Family History: } \\
\hline Dystonia $^{\ddagger}$ & 1 & 1 & 1 & 0 & 1 & 0 \\
\hline Tremor & 0 & 1 & 2 & 0 & 3 & 0 \\
\hline
\end{tabular}

${ }^{*}$ Mean dose in 3 patients $=19.3 \mathrm{mg}$; fourth patient with cranial dystonia was treated with ethopropazine $450 \mathrm{mg} / \mathrm{d}$

+ One patient reached $14 \mathrm{mg}$ of trihexyphenidyl with almost complete remission in torticollis which persisted after drug dosage was reduced (see text)

SWC $=$ simple writer's cramp

${ }^{\ddagger}$ All four patients had inheritance compatible with an autosomal dominant trait including one patient of Ashkenazi Jewish origin

See text for details of response categories

(Table 5). Side effects caused three to lower the dosage, and three to stop the drug (one with marked benefit on ethopropazine and two with a moderate response). One patient with severe spasmodic torticollis had almost a complete resolution of symptoms with $14 \mathrm{mg}$ of trihexyphenidyl. This benefit persisted when the dosage was reduced to $6 \mathrm{mg}$ per day (mild symptoms returned on doses lower than this).

The remaining $22(63 \%)$ had little or no improvement. One of these patients with prominent oromandibular dystonia and minimal blepharospasm had a marked increase in the severity of blepharospasm with $6 \mathrm{mg}$ of trihexyphenidyl per day. This increase in symptoms persisted for several weeks after the drug was withdrawn. Three patients with a mild benefit $(+)$ continued to take trihexyphenidyl in lower doses while the remainder of this group discontinued the drug.

The age of onset of dystonia, the age at the beginning of treatment and the severity of dystonia did not correlate with the response to therapy. The presence of tremor in the patient or their family and a family history of dystonia also failed to predict the response to anticholinergic therapy. Patients with a marked response had a much shorter duration of dystonia than other groups (Table 2$)$. When marked and moderate $(+++$ and ++ ) response groups were combined, the mean duration of dystonia was 4.7 years compared to 5.7 years in patients with poorer responses.

The highest doses (up to $70 \mathrm{mg}$ ) were taken by patients under the age of 30 . Overall, younger patients tended to tolerate slightly higher doses than older patients. No patient over the age of 40 tolerated a dosage of greater than $30 \mathrm{mg} / \mathrm{d}$. Good responses tended to occur with higher doses. Patients obtaining a moderate response $(+++$ or ++$)$ took a mean dosage of $23.3 \mathrm{mg}$ (range 6-70; median $20 \mathrm{mg}$ ) while those with lesser responses $(+,+/-, 0,-)$ took a mean dosage of $15.7 \mathrm{mg}$ (range 4-45; median $12 \mathrm{mg}$ ). $10 \mathrm{mg}$ or less was the maximum tolerated dose in four of ten non-responders, two of nine patients with a moderate response $(++$ ) (one taking concomitant haloperidol $2.5 \mathrm{mg}$ ) and one of six patients with a minimal response $(+/-)$.

Three patients (one spasmodic torticollis, one segmental and one generalized dystonia) who experienced no benefit before the development of intolerable side effects with trihexyphenidyl ( $12 \mathrm{mg}, 6 \mathrm{mg}$ and $8 \mathrm{mg}$ respectively) had similar results with ethopropazine (200 mg, $150 \mathrm{mg}$ and $200 \mathrm{mg}$ respectively).

\section{Symptomatic Dystonia}

None of the nine patients with symptomatic dystonia obtained a moderate or marked response (Table 3 ). Three (33\%) had a mild benefit and one of these patients with generalized dystonia due to metachromatic leukodystrophy ${ }^{5}$ continued to take the drug at a lower dosage. The remainder of the patients, including all three with hemidystonia (two following stroke and one post traumatic), had little or no benefit before the development of intolerable side effects. One patient with tardive cranial dystonia had a mild to moderate increase in his symptoms which subsided quickly after the drug was withdrawn.

The number of patients involved was too small to provide useful data on the importance of age of onset and duration of 


\begin{tabular}{|c|c|c|c|c|}
\hline Response & + & $+1-$ & 0 & - \\
\hline Age of Onset (yrs) & $\begin{array}{l}21 \\
(8-29)\end{array}$ & 30 & $\begin{array}{c}43.8 \\
(6-64)\end{array}$ & 53 \\
\hline Duration of Dystonia (yrs) & $\begin{array}{l}15 \\
(2-34)\end{array}$ & 1 & $\begin{array}{c}6.1 \\
(0.5-9)\end{array}$ & 4 \\
\hline Mean Dosage (mg) & $\begin{array}{c}21.3 \\
(14-30)\end{array}$ & $\begin{array}{c}12 \\
\text { (Cogentin) }\end{array}$ & $\begin{array}{c}14.5 \\
(2-24)\end{array}$ & 12 \\
\hline Median Dosage (mg) & 20 & - & 21 & 一 \\
\hline Tardive: Segmental & 2 & 1 & - & 一 \\
\hline Cranial & - & - & 1 & 1 \\
\hline Hemidystonia & - & - & 3 & 一 \\
\hline MLD* & 1 & - & - & 一 \\
\hline Total $(\%)$ & $\begin{array}{c}3 \\
(33)\end{array}$ & $\begin{array}{c}1 \\
(11)\end{array}$ & $\begin{array}{c}4 \\
(44)\end{array}$ & $\begin{array}{r}1 \\
\text { (11) }\end{array}$ \\
\hline
\end{tabular}

${ }^{*}$ Metachromatic Leukodystrophy ${ }^{5}$

dystonia to the response of trihexyphenidyl. The median dosage was similar in the patients obtaining a mild response and those with no benefit. This dosage was the same as that used in the patients with idiopathic dystonia who has obtained a moderate or marked response (Table 2).

\section{Side Effects and Outcome (Tables 4 and 5)}

Table 4 outlines the side effects occurring in all 44 patients. Only four patients had no side effects whatsoever. Of the eight patients who remained on trihexyphenidyl but at a lower dos-

\begin{tabular}{llll}
\hline Table 4: Side Effects* & & & \\
\hline \hline Drowsiness & 7 & Dry mouth & 9 \\
Altered sensorium ${ }^{+}$ & 5 & Blurred vision & 7 \\
$\begin{array}{l}\text { Dizziness/decreased } \\
\quad \text { coordination }\end{array}$ & 3 & Difficulty voiding & 3 \\
Difficulty sleeping & 2 & Nausea & \\
Agitation & 2 & Constipation & 2 \\
Light headed & 2 & Diarrhea & 1 \\
Chorea & 1 & Skin Rash & 1 \\
\hline
\end{tabular}

*Several patients had more than one side effect

+" High" sensation, difficulty concentrating, or "don't feel right" age because of side effects (category B, Table 5), six had experienced "peripheral" complications and two "central". Of the 30 patients who discontinued the anticholinergic before or after obtaining benefit from the drug, nine withdrew because of "peripheral" side effects and 21 because of "central" side effects or equally severe "central" and "peripheral" complications.

\section{Discussion}

Fahn was the first to study the use of high doses of anticholinergics in dystonia'. He subsequently published results of an open study in a large group of children and adults with various forms of dystonia $^{3}$ as well as a supporting smaller doubleblind study. ${ }^{2}$ Marsden and his colleagues have recently reported their experience with severe dystonia in children and adults. ${ }^{4}$ This paper also reviewed their previous published and unpublished results with similar therapy in adult-onset focal dystonia. The results of the present study are in general agreement with those obtained by these two groups. Thirty per cent of my patients with idiopathic generalized and segmental dystonia obtained a useful response while $40 \%$ of similar patients in Fahn $^{3}$ and Marsden et al's ${ }^{4}$ studies benefited. Figures of $42 \%$ for spasmodic torticollis and $33 \%$ for writer's cramp and focal arm dystonia are similar to those from the earlier studies. Fifty per cent of the present cranial dystonia (Meige syndrome) patient group benefited. This is similar to Fahn's result of $43 \%$ but much higher than the $12 \%$ reported by Marsden et al. This may relate to lower doses of anticholinergics used in these patients who were reviewed retrospectively. 4.8 .9

Dosages tolerated by the patients were lower in the present study than in the two previous reports. Those remaining on the drug and continuing to benefit took $20 \mathrm{mg}$ of trihexyphenidyl compared to $24 \mathrm{mg}$ in Fahn's study and $56.1 \mathrm{mg}$ in Marsden et al's. This may be related to the higher proportion of older patients with adult-onset focal dystonia in the present report. This fact may also account for the higher proportion of patients withdrawn from treatment because of side effects; $68 \%$ in the present study compared to 50\% of Fahn's and 30\% of Marsden et al's patients. Both previous reports found that children tolerated higher dosages and had a better response than adults. No children were treated in the present study. However, in agreement with these reports, younger patients tolerated the highest doses and good responses tended to occur (not invariably) with higher doses.

\begin{tabular}{|c|c|c|c|c|c|c|c|c|}
\hline$+1+1-10 /-$ & 31 & 0 & 4 & 2 & 2 & 6 & $15^{*}$ & 2 \\
\hline
\end{tabular}

\footnotetext{
*Includes 2 patients whose dystonia was increased with trihexyphenidy!

$A=$ improved and continuing on maximum dosage

$\mathrm{B}=$ improved with side effects, continuing on lower dosage

C = improved but with intolerable side effects causing drug withdrawal

D = no improvement before development of intolerable side effects
} 
In agreement with Fahn but not with Marsden et al, symptomatic hemidystonia failed to respond to anticholinergic therapy. Contrary to Fahn's results, an autosomal dominant family history of dystonia did not necessarily correlate with a good response.

The severity of dystonia increased in two patients on low doses ( 6 and $12 \mathrm{mg}$ ) of trihexyphenidyl. Both withdrew from the study, however, the worsening in symptoms persisted for several weeks in one patient. Fahn ${ }^{3}$ found that an initial worsening in the dystonia was not necessarily associated with a poor response to therapy. This could not be confirmed because neither of these patients returned to anticholinergic medication at a later date.

One patient with spasmodic torticollis obtained a marked response with $14 \mathrm{mg}$ of trihexyphenidyl. This benefit persisted despite a reduction in dose to $6 \mathrm{mg}$ because of side effects. Previously she had failed to respond to several other medications. Improvement with anticholinergic therapy occurred gradually and in increments related to dosage increases. This response might be considered a "drug-induced remission" as reported previously in spasmodic torticollis. ${ }^{10}$ All other patients responding to high doses of anticholinergics showed a progressive increase in dystonia towards baseline severity when the dosage was lowered.

Seventy per cent of the patients in the present report who withdrew due to side effects had experienced "central" complications compared to $52 \%$ in Fahn's study. ${ }^{3}$ This still leaves a significant number who might have benefited from the addition of a peripherally active cholinergic agonist as reported in one patient with cranial dystonia by Duvoisin. ${ }^{11}$

Some acute studies using intravenous anticholinergics in cranial dystonia and spasmodic torticollis have reported significant beneficial responses with subsequent improvement in most of these responders when treated with chronic oral therapy. ${ }^{12,13,14}$ However, Lang and colleagues obtained only limited benefit, much of which could have been explained on the basis of drug-induced sedation. ${ }^{8}$ This is in marked contrast to the numbers of patients responding to high dose oral anticholinergic therapy which is increased slowly to avoid the development of early side effects. This discrepancy suggests that using an acute intravenous challenge of anticholinergics would probably fail to predict the response to high dose oral therapy.

The pathology and biochemistry of idiopathic dystonia are unknown. Study of symptomatic hemidystonia patients with similar abnormal movements and postures indicates that dysfunction of striatal projections from either caudate or putamen (via globus pallidus) to thalamus or the thalamus itself may be important. ${ }^{15}$ How high dosage anticholinergic therapy alters the resulting abnormal input to premotor and motor cortex to improve dystonia is unknown. Maltese and his colleagues ${ }^{16}$ have recently excluded the possibility of a generalized acetylcholinesterase deficiency which might account for the response to this therapy.

Because of our ignorance regarding the mechanisms underlying dystonia, treatment is often unsatisfactory. A wide variety of drugs have been tried but usually without success. ${ }^{17}$ Benzodiazepines are commonly used but rarely result in more than a mild benefit. Dopamine antagonists are often helpful but their potential for causing disabling early (e.g., acute dystonic reactions, akathisia, parkinsonism) and long-term (e.g., tardive dyskinesia) adverse effects is great. Although side effects from anticholinergic therapy are frequent, they tend to be less severe or long- lasting than those caused by dopamine antagonists. This may not be the case for the possible long-term cognitive effects of high dose anticholinergic therapy which remain to be studied. ${ }^{4}$ The potential benefit that might be obtained from high-dosage anticholinergic therapy as shown in this and previous studies indicates that this should be the first line therapy in patients with disabling dystonia. The response of dystonia to the standard lower doses of anticholinergics is usually poor ${ }^{8,18}$ It is important to review the maximum dosage and speed of dose increase in all patients said to have previously failed anticholinergic therapy. Given the benefit of another trial of higher doses with slow dosage increments, some of these anticholinergic "failures" may obtain a gratifying response.

\section{ACKNOWLEDGEMENTS}

Thanks to Dr. R.D.G. Blair for reviewing the manuscript and giving helpful comments and Mrs. T. Pugh for secretarial assistance.

\section{REFERENCES}

1. Fahn S. Treatment of dystonia with high-dosage anticholinergic medication. Neurology (NY) 1979; 29: 605.

2. Burke RE, Fahn S. Double-blind evaluation of trihexyphenidyl in dystonia. Adv Neurol 1983; 37: 189-192.

3. Fahn S. High dosage anticholinergic therapy in dystonia. Neurology (Cleveland) 1983; 33: 1255-1261.

4. Marsden CD, Marion M-H, Quinn N. The treatment of severe dystonia in children and adults. J Neurol Neurosurg Psychiatry 1984; 47: 1166-1173.

5. Lang AE, Clarke JTE, Resch L, Strasberg P, Skomorowski MA, O'Connor P. Progressive longstanding "pure"' dystonia - a new phenotype of juvenile metachromatic leukodystrophy. Neurology (Cleveland) 1985; 35 (suppl 1): 194.

6. Segawa M, Hosaka A, Miyagawa F, Nomura Y, Imai H. Hereditary progressive dystonia with marked diurnal fluctuations. Adv Neurol 1976; 14: 215-233.

7. Sunohara N, Mano Y, Ando K, Satoyoshi E. Idiopathic dystoniaparkinsonism with marked diurnal fluctuation of symptoms. Ann Neurol 1985; 17: 39-45.

8. Lang AE, Sheehy MP, Marsden CD. Anticholinergics in adultonset focal dystonia. Can J Neurol Sci 1982; 9: 313-319.

9. Marsden CD, Lang AE, Sheehy MP. Pharmacology of cranial dystonia. Neurology (NY) 1983; 33: 1100-1101.

10. Lang $A E$, Marsden $C D$. Alphamethylparatyrosine and tetrabenazine in movement disorders. Clin Neuropharmacol 1982; 5: 375-387.

11. Duvoisin RC. Meige syndrome: relief on high-dose anticholinergic therapy. Clin Neuropharmacol 1983; 6: 63-66.

12. Lal S, Hoyte K, Kiely ME, Sourkes TL, Baxter DW, Missala K, Anderman F. Neuropharmacological investigation and treatment of spasmodic torticollis. Adv Neurol 1979; 24: 335-351.

13. Tanner CM, Glantz RH, Klawans HL. Meige disease: acute and chronic cholinergic effects. Neurology (NY) 1982; 32: 783-785.

14. Tanner CM, Goetz CS, Weiner WJ, Nausieda PA, Wilson R, Klawans HL. The role of cholinergic mechanisms in spasmodic torticollis. Neurology (NY) 1979; 29: 604-605.

15. Marsden CD, Obeso JA, Zarranz JJ, Lang AE. The anatomical basis of symptomatic dystonia. Brain 1985; 108: 463-483.

16. Maltese WA, Bressman S, Fahn S, DeVivo DC. Acetylcholinesterase activity in patients with torsion dystonia. Arch Neurol 1985; 42: 154-155.

17. Marsden CD. Treatment of torsion dystonia. In: Barbeau A, ed. Disorders of Movement. Lancaster: MPT Press 1981: 81-104.

18. Nutt JG, Hammerstad JP, de Garma P, Carter J. Cranial dystonia: double-blind crossover study of anticholinergics. Neurology (Cleveland) 1984; 34: 215-217. 